Iranian Journal of Breast Diseases. 2020; 13(2):37-48.

\section{Original Article \\ Toxicity Effect of Bromoacetic Acid on MCF7 Breast Cancer Cell Line and Analysis of Expression of Apoptosis-Associated Genes}

\author{
Bahman Jahromi $E^{1}$, Jafaarnejad L ${ }^{2}$, Vahdani $\mathbf{M}^{2}$, Zolghadri $S^{1^{*}}$ \\ ${ }^{1}$ Department of Biology, Jahrom Branch, Islamic Azad University, Jahrom, \\ Iran \\ ${ }^{2}$ Msc Student, Department of Biology, Jahrom Branch, Islamic Azad \\ University, Jahrom, Iran
}

Receive: $12 / 8 / 2019$ Accepted: 1/3/2020

*Corresponding Author: szjahromi@yahoo.com

Ethics Approval: Not applicable

\section{Abstract}

Introduction: Cancer, the uncontrolled division of cells, occurs because of environmental factors and genetic disorders. Breast cancer is the most common cancer and the second leading cause of cancer death in women. Four categories of key genes, including oncogenes, tumor suppressor genes, repairing genes, and programmed- cell death genes, contribute to cancer development. Bromoacetic acid is a chemical compound that is produced both artificially and by bacterial fermentation.

Methods: To investigate the effectiveness of bromoacetic acid in inhibiting the MCF7 cell line proliferation, the MTT assay was done and the expression of genes responsible for the regulation of apoptosis, including $B A K, C A S P 3, C A S P 8$, and $B I M$, was measured after 24,48 , and 72 hours of cell treatment with $2.5 \mu \mathrm{g} / \mathrm{ml}$ of bromoacetic acid using real-time PCR.

Results: The results of the gene expression assays showed that bromoacetic acid treatment increased the expression of key genes $B A K, C A S P 3$, and, CASP8. However, the expression of BIM decreased at all three time points compared with controls.

Conclusion: bromoacetic acid can induce cell death via intrinsic and extrinsic apoptosis pathways.

Keywords: Breast Cancer, Gene Expression, Bromoacetic Acid 


\section{MCF7}

عنايت الله بهمن جهرمى'، ليلا جعفرنزاد'، مينا وحدانى'، سمانه ذوالقدرى '

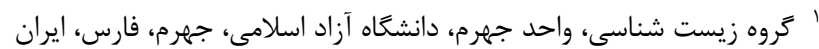

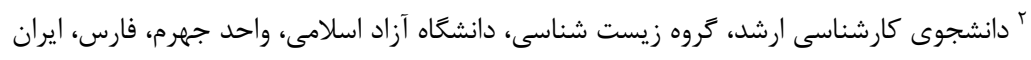

\section{"جكيله}

مقدمه: سرطان، تقسيم غيرقابل كنترل سلولها، در اثر عوامل محيطى و اختلال هاى زنتيكى

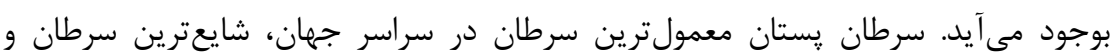

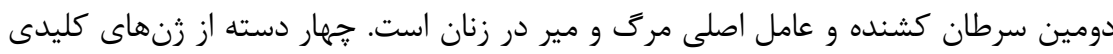

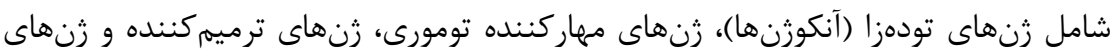

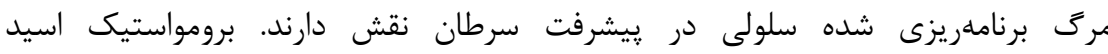

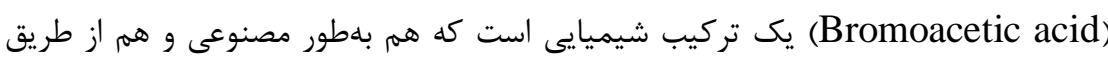
تخمير باكتر يايى، توليد مىشود. روش بررسى: براى بررسى اثر برومواستيك اسيد بر ممانعت از تكثير رده سلول سرطانى

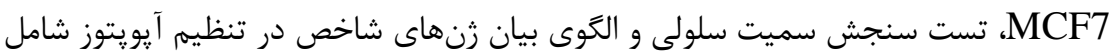
CASP3، BAK

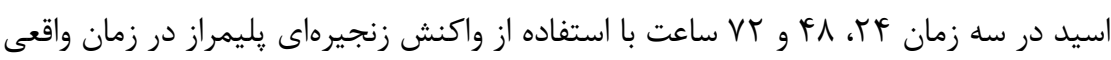
اندازمكيرى شد.

يافتهها: نتايج بررسى الكَى بيان زن نشان داد تحت تيمار برومواستيك اسيد، ميزان بيان

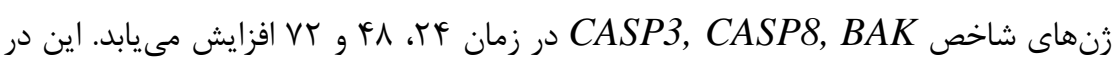
حالى است كه بيان زن BIM نسبت به كنترل در هر سه زمان كاهش مي إبابد. نتيجهَيرى: برومواستيك اسيد مركى سلولى را از طريق مسيرهاى درونى و بيرونى آيإِوز

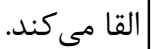
|وازههاى كليدى: سرطان بـتان، بيان زن، برومواستيك اسيد

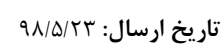
تاريخ هذيرش: IN/IT/II

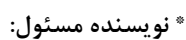
szjahromi@yahoo.com 
القاى صدمه ميتوكندريايى و فشرده شدن هسته سلول

منتقل مىشود و به دنبال آن ضدآيويتيكها به نام Bcl2

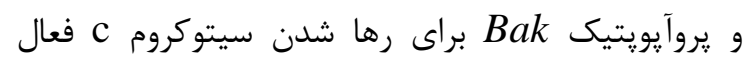

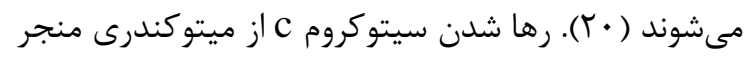

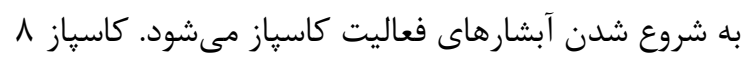
و 9 باعث فعال شدن كاسياز r شده و اين كاسياز قابليت

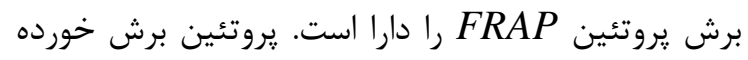

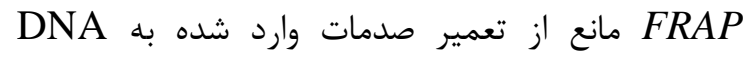
مىشود و در نتيجه آيويتوز القامىشود (I) تعمات جهت بررسى خواص ضدسرطان احتمالى از طريق بررسى

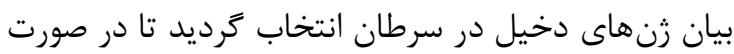

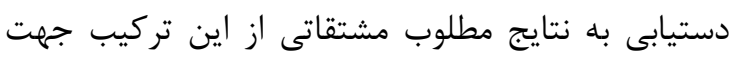
ارزيابى اثرات ضدسرطانى طراحى و سنتز شوند.

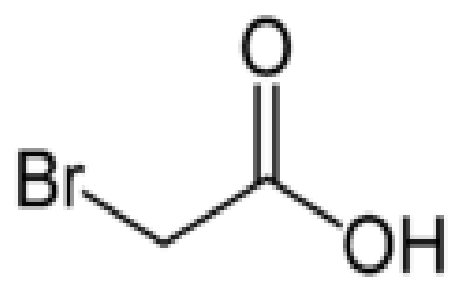

شكل ז: ساختار شيميايى برومواستيك اسيد
توانايى سلولهاى سرطانى در مقاومت در برابر مرى سلولى امروزه به عنوان يك معضل بزرى بـ به شمار مى آيد. بر اساس مطالعاتى كه محققان مختلف انجام دادهاند

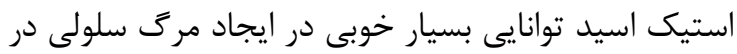
سلول هاى مختلف سرطانى را دارد (1، ؟).

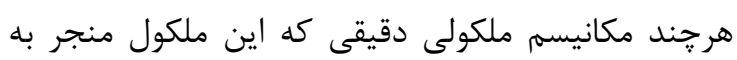

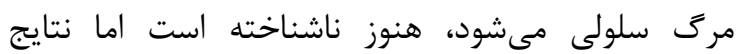
تحقيقات نشان مىدهد اين ملكول ضمن ايجاد استرس

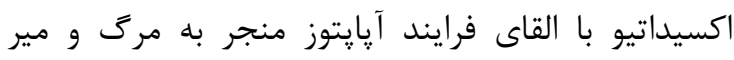

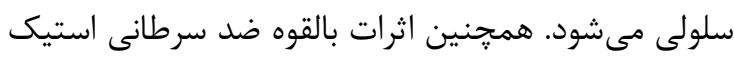
اسيد در مدلهاى حيوانى، آن را به تنهايى و يا دان درد

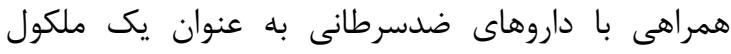

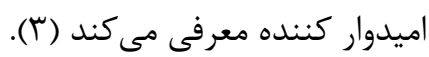

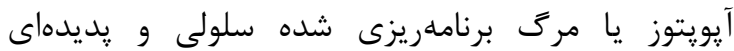

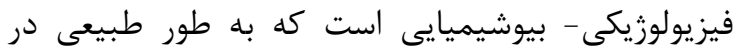

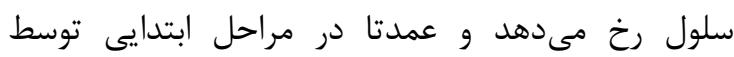

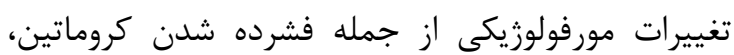

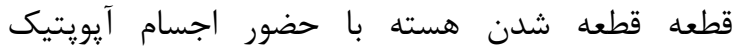

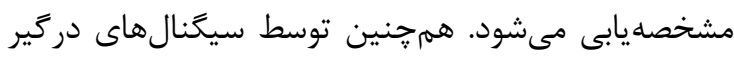

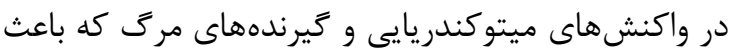
فعال نمودن كاسياز مىشود مشخصهيابى مىشود (\&).

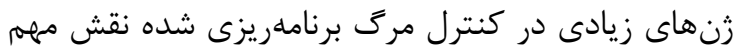

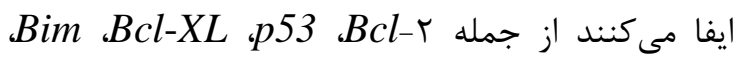
و Bak Bad فاكتورها در تنظيم يروسه آيويتوز نقش دارد كه از آن آن

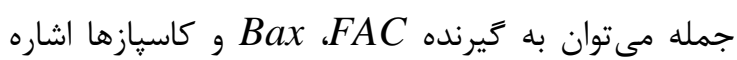

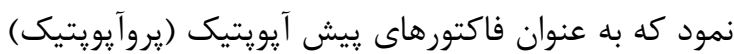

هستند (r) (19) - (19).

آيويتوز توسط دو مسير intrinsic (هدايت شده توسط (هئ (هد)

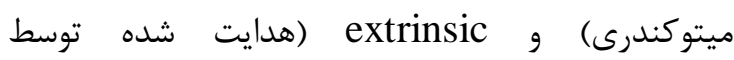

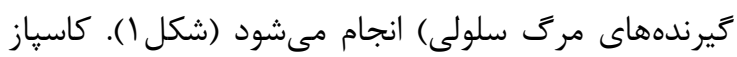

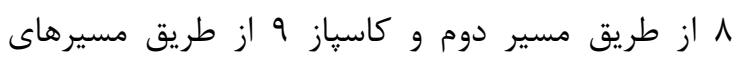

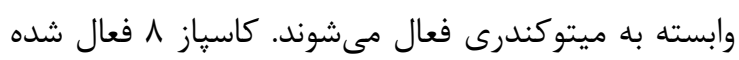
مى تواند دو نوع سيكنال آيويتيك مختلف را فعال نمايد كه به طور مستقيم باعث فعال شدن كاسياز r م و برش

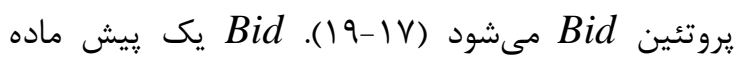

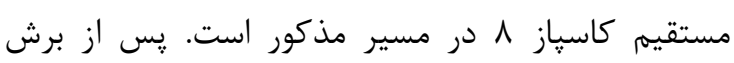

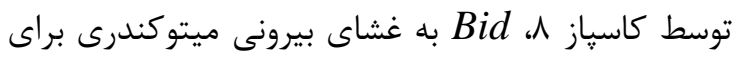


در نهايت از روى نمودار رسم شده مقدار IC50 نمونهها

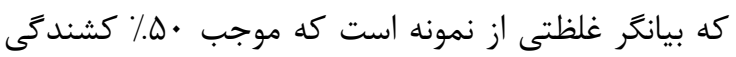
سلول هاى سرطانى مىشود، محاسبه شد (YT). تيمار سلولها با برومو استيك اسيد براى استخراج

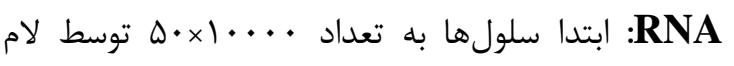

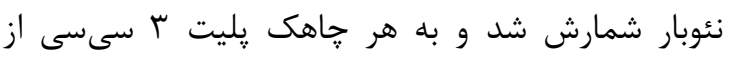

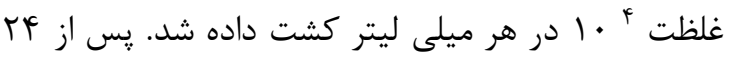

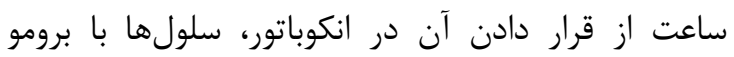

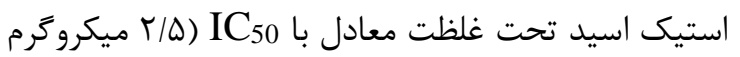

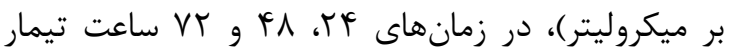

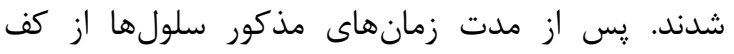

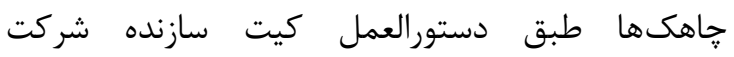
جا

$$
\text { استخراج RNA آماده شد. }
$$

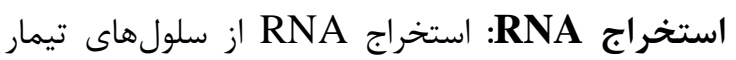
شده و تيمار نشده توسط كيت Ribospin

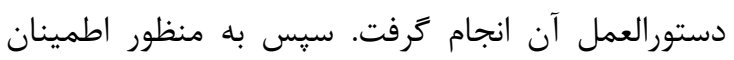

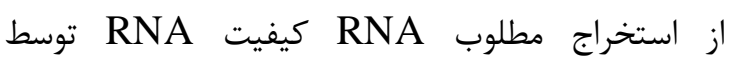
روش الكتروفورز زل آكارز مورد بررسى قرار ترات

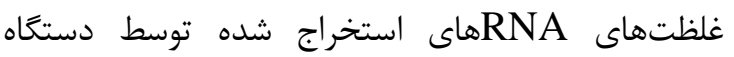
نانودراب Biotek (Epoch) اندازه خيرى شد. ساخت CDNA: در اين مرحله از كيت شركت Geneall

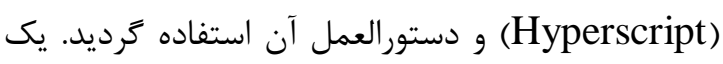
ميكرو

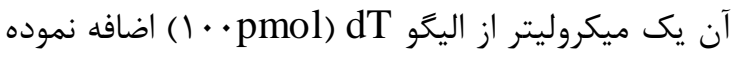

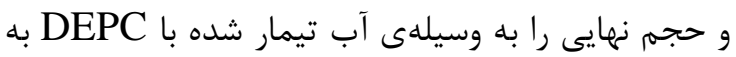

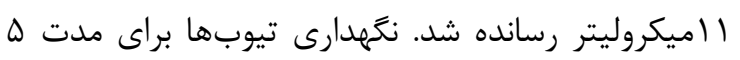

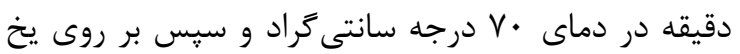

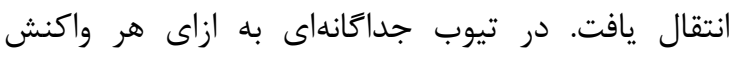

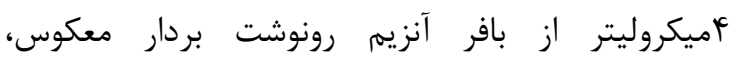

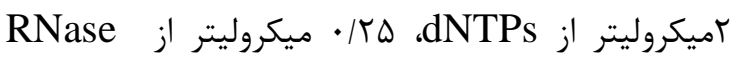

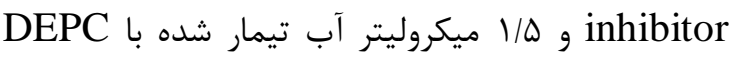
ريخته شد. از مسترميكس \ ميكروليتر به هر تيوب اضافه

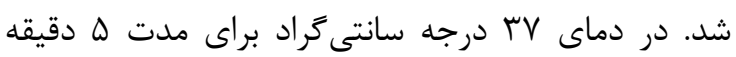

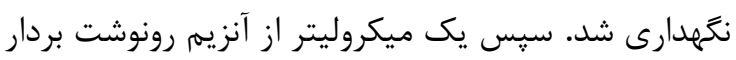

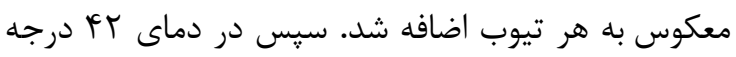

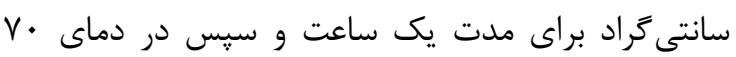

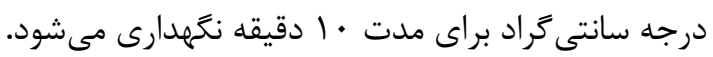

\section{مواد و روشها}

اين مطالعه تجربى آزمايشعاهى از ارديبهشت تا بهمن

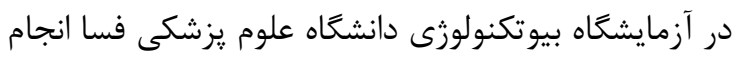

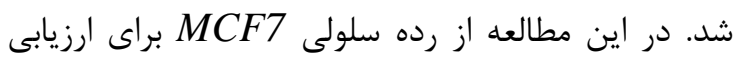

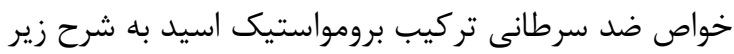

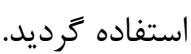

كشت سلولى: رده سلولى MCF7 از دانشگاه علوم

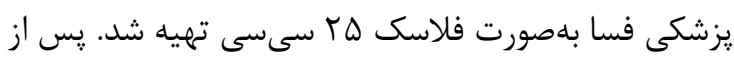
جابهجايى براى جلوكيرى از عدم صدمه به سلولها، به به

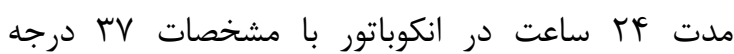
سانتى

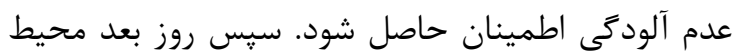

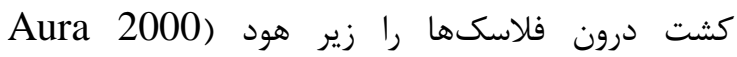

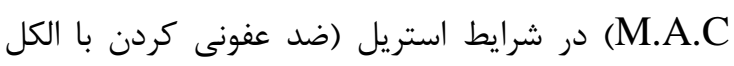

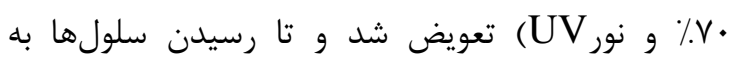

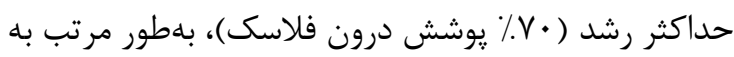

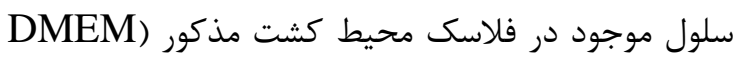

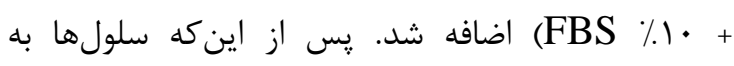

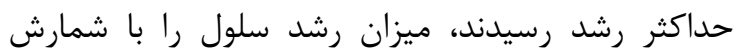

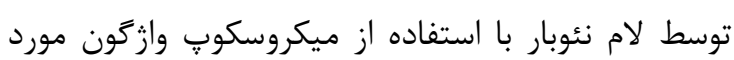

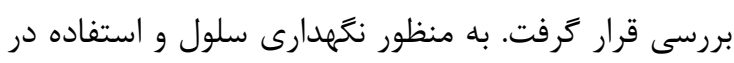

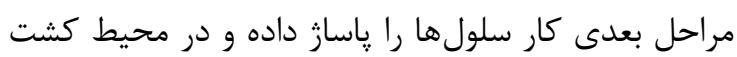

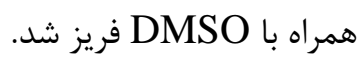

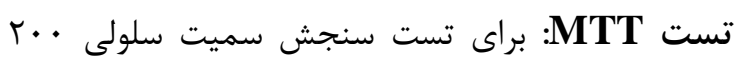

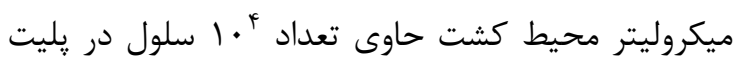

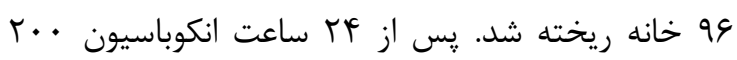

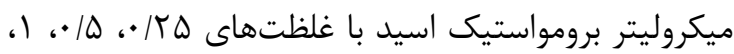

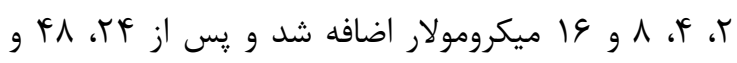

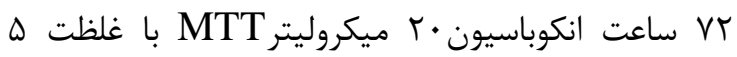

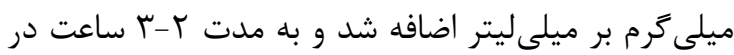

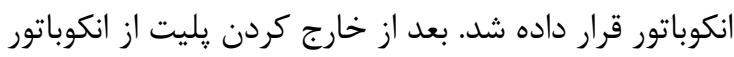

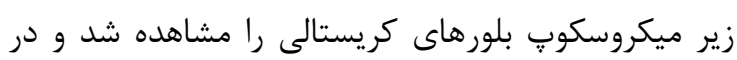

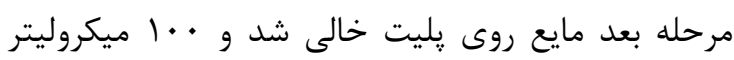
محلول رقيق DMSO براى حل كردن بلورهاى فوماران

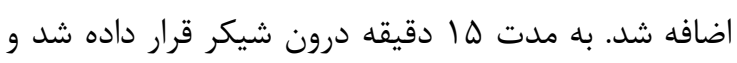

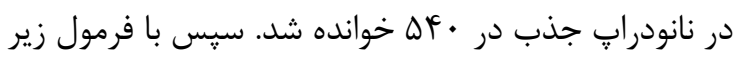
درصد كشندگى حساب شد.

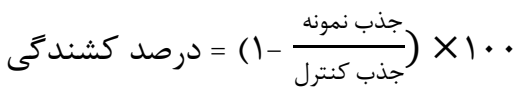


آناليز آمارى: تمامى آناليزهاى MTT در V تكرار انجام

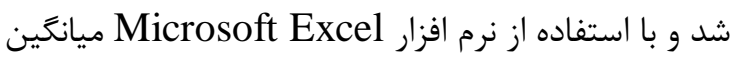

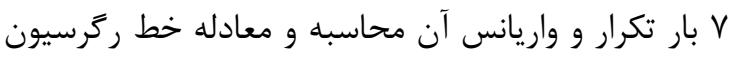
غلظت در برابر درصد كشندگى به دست آمدا برأ براى مطالعه

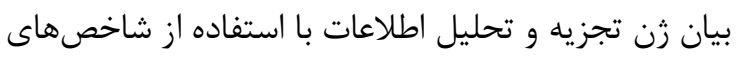

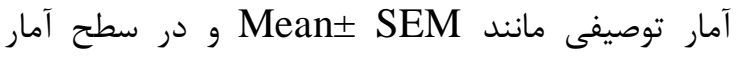

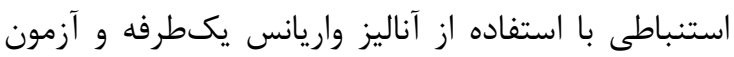

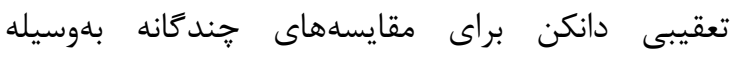
نرمافزار SPSS ورزن آ و ترسيم نمودارها با اكسل انجام شد. سطح معنى دارى ه • • در نظر كرفته شد.
آغازكرهاى مورد استفاده: ليست : برايمرهاى مورد استفاده در جدول البه نمايش كذاشته شده است.

مراحل واكنش Real time PCR: واكنش Real time PCR كشور آمريكا و با روش

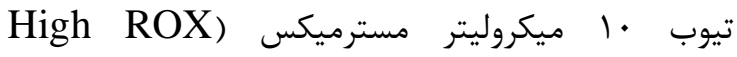
Real Q Plus 2x mastermix Green، شركت AMPLIQON ) ، ميكروليتر حاوى هـ نانوگرم CDNA

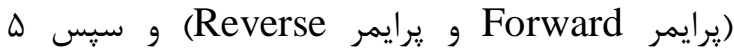
ميكروليتر آب مقطر به تيوب اضافه شد.

جدول ا: ليست يرايمرهاى مورد استفاده

\begin{tabular}{|c|c|c|c|}
\hline NO. & Name & Sequence & Reference \\
\hline 1 & $\mathrm{P} 21-1$ & CACTCCAAACGCCGGCTGATCTTC & $(T r)$ \\
\hline 2 & $\mathrm{P} 21-2$ & TGTAGAGCGGGCCTTTGAGGCCCTC & \\
\hline 3 & Caspases3-1 & AAGCGAATCAATGGACTCTGG & $(T F)$ \\
\hline 4 & Caspases3-2 & CTGTACCAGACCGAGATGTC & \\
\hline 5 & Caspases8-1 & CCAGAGACTCCAGGAAAAGAGA & $(T \Delta)$ \\
\hline 6 & Caspases8-2 & GATAGAGCATGACCCTGTAGGC & \\
\hline 7 & Bak-1 & ATGGTCACCTTACCTCTGCAA & $(\uparrow \varepsilon)$ \\
\hline 8 & Bak-2 & TCATAGCGTCGGTTGATGTCG & \\
\hline 9 & bim-1 & GAATCCACTTCGCTCCGCGCAGCCGCCTGGT & $(T V)$ \\
\hline 10 & bim-2 & GGATCCTTGGTCTTTTTTTCTTGCGTTTCTC & \\
\hline 11 & Bactin $1-1$ & TACCCAGGCATTGCTGACAGG & $(\curlyvee \wedge)$ \\
\hline 12 & Bactin $1-2$ & ACTTGCGGTGCACGATGGA & \\
\hline
\end{tabular}

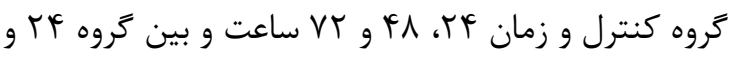
يافتهها

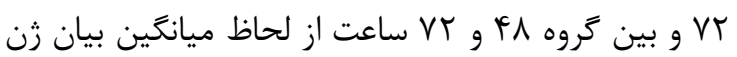

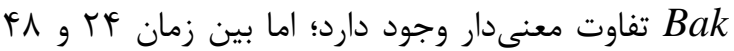

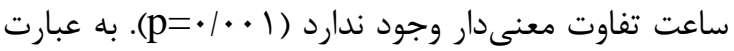

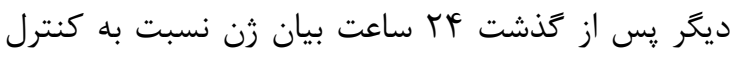

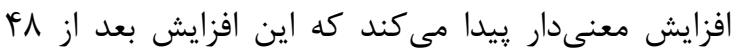

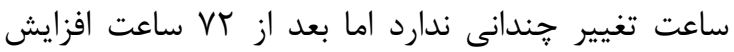

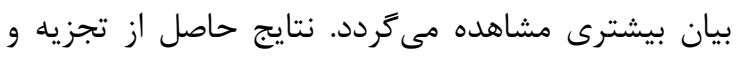
تحليل بيان زن Caspase3 نشان داد كه بين بين كردود

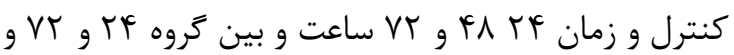

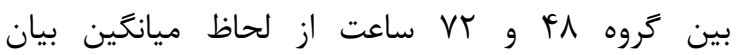
زن Caspase3 تفاوت معنى دار وجود دارد؛ اما بين زمان

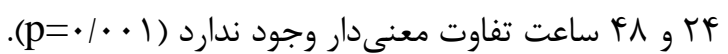
سنجش MTT: نمودار 1 مقايسه اثر زمان بر درصد

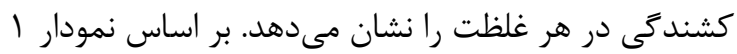
برومواستيك اسيد در هر سه زمان، بيشترين ميزان

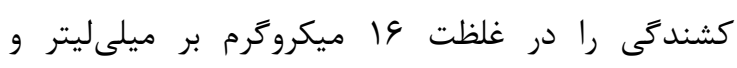
كمترين ميزان كشند

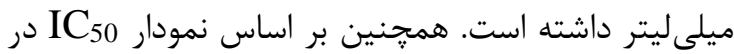

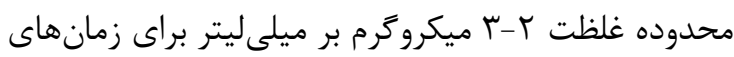

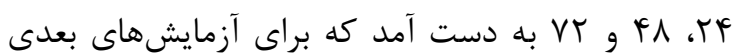

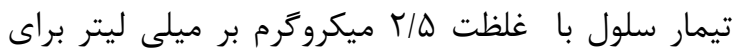
هر سه زمان استفاده شد.

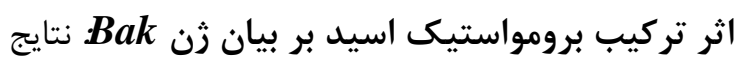

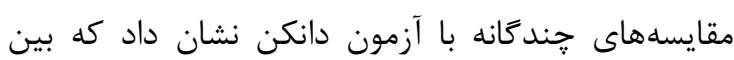



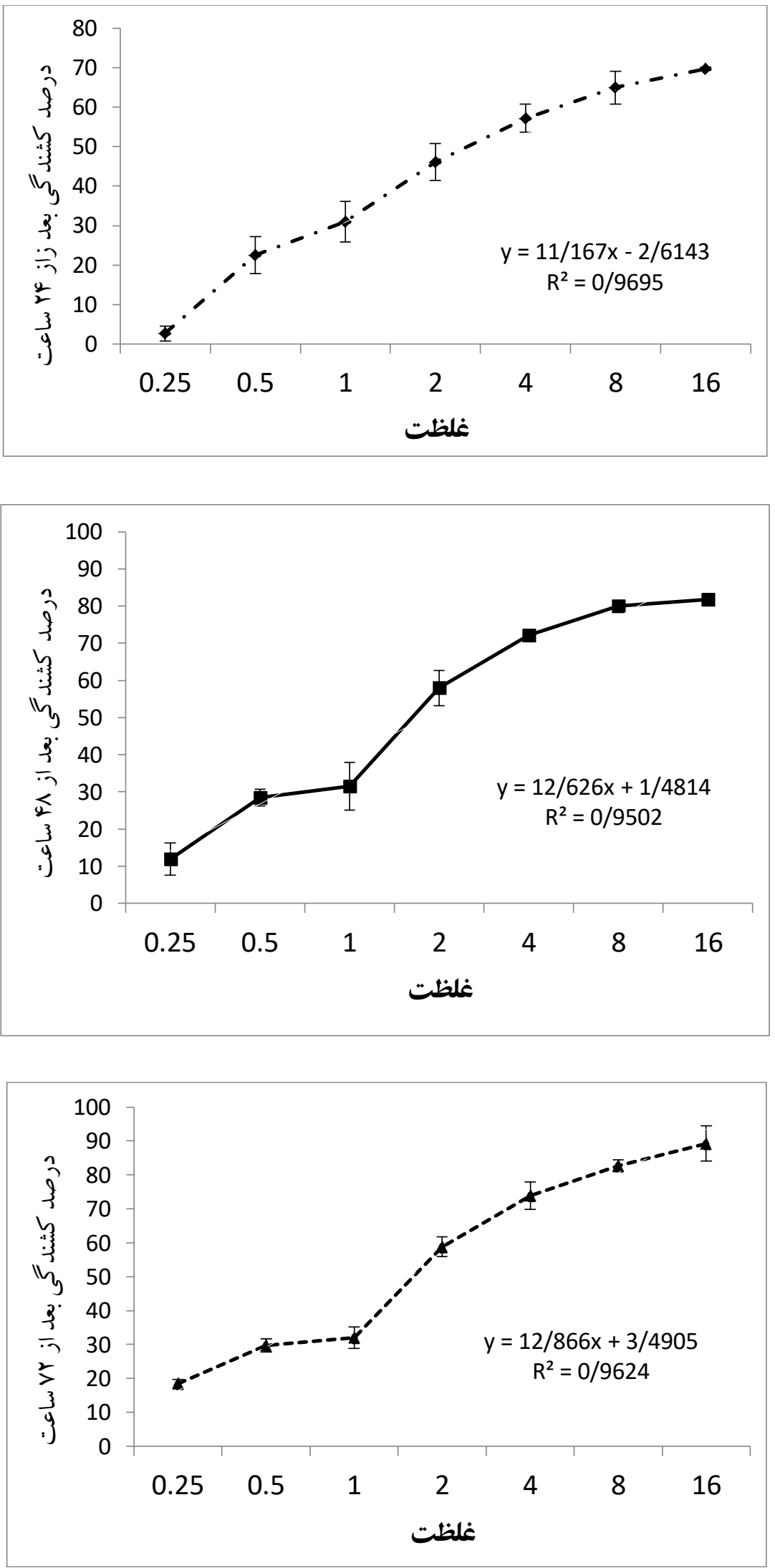

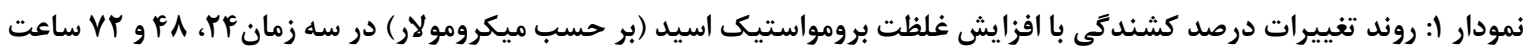




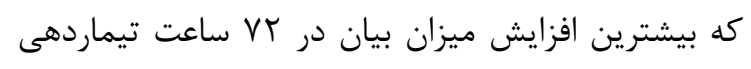

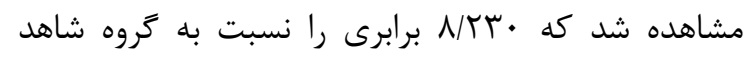

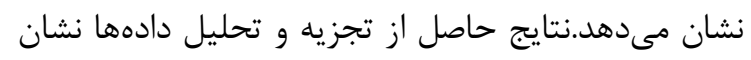

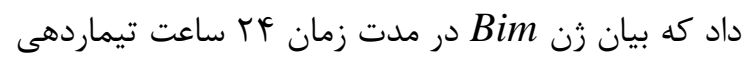

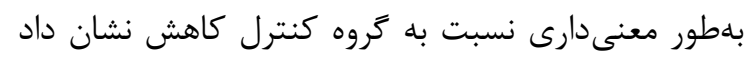

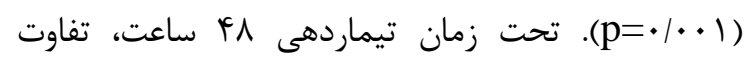

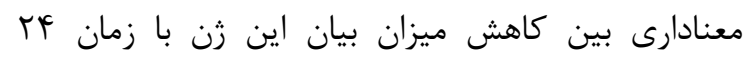

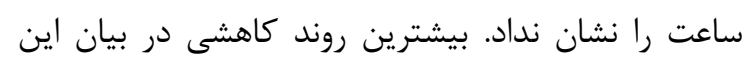

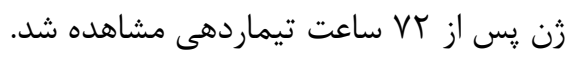

به عبارت ديخر يس از كذشت بF ساعت بيان زن نسبت

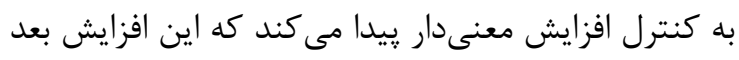

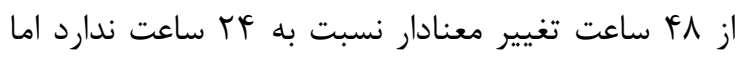

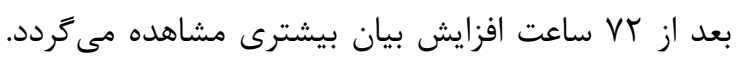

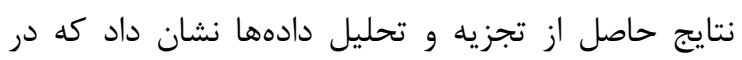

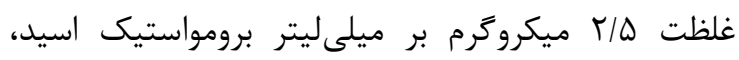

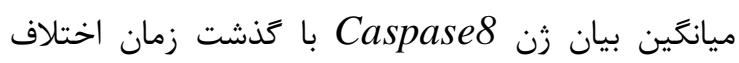

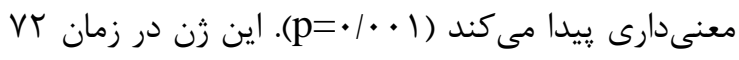

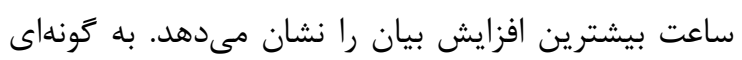

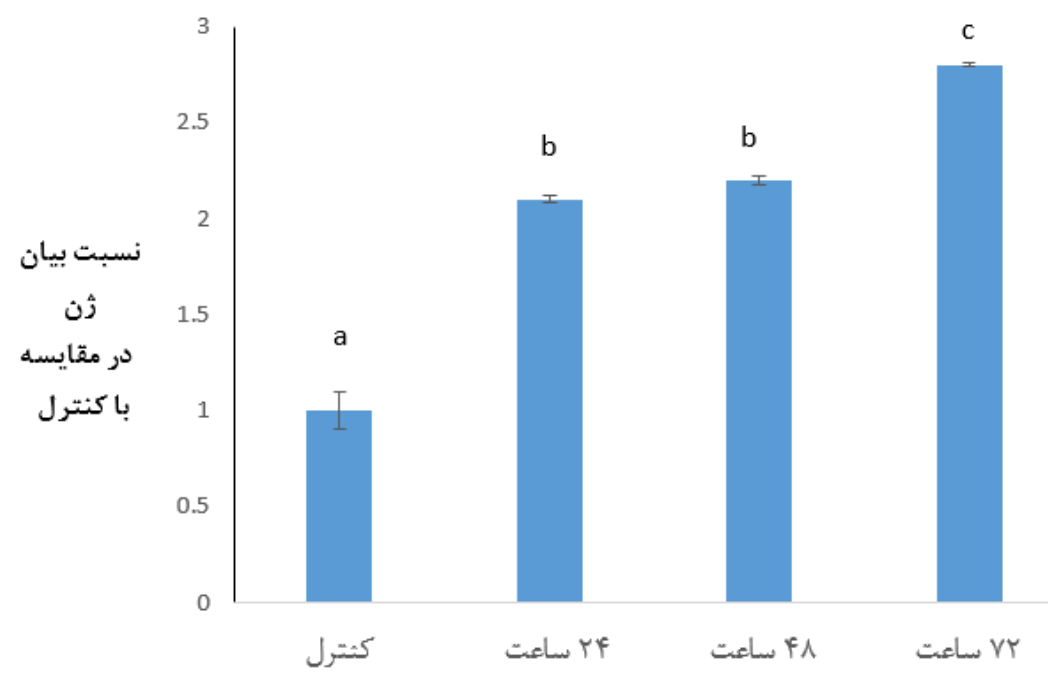

نمودار ז: آناليز مقايسهى بيان ثن Bak به روش ريل تايم در سلول MCF7 در غلظت

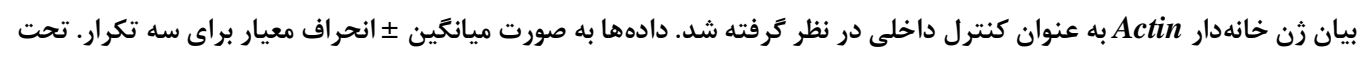

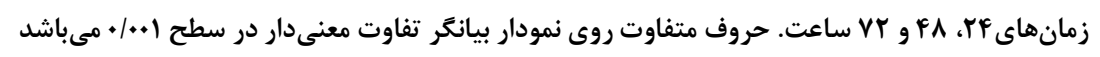

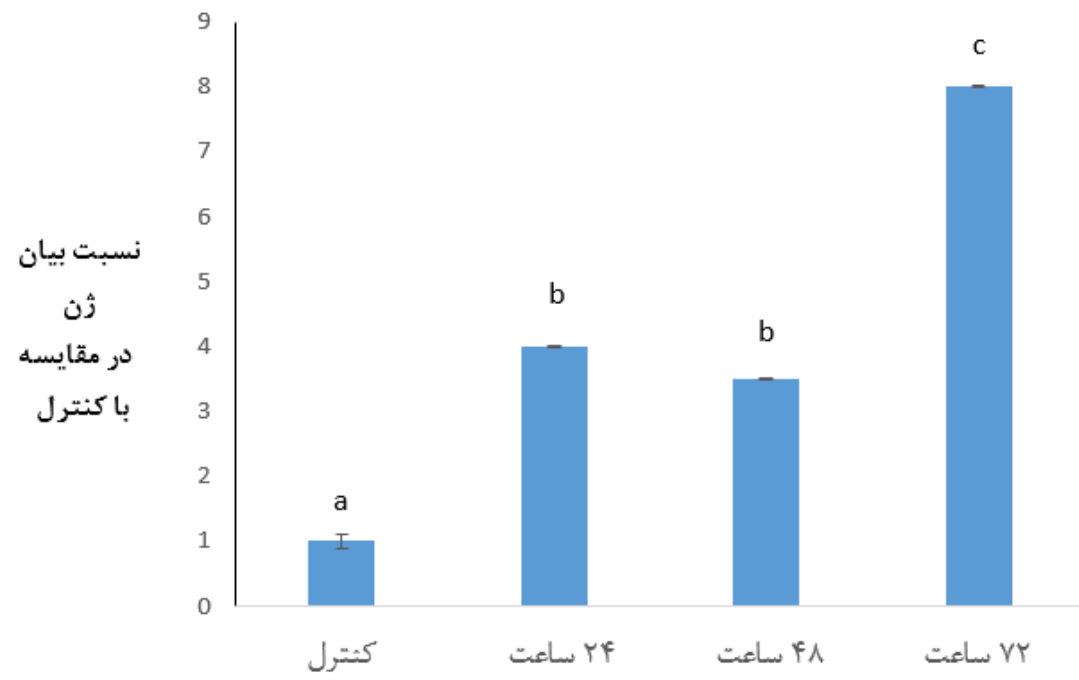

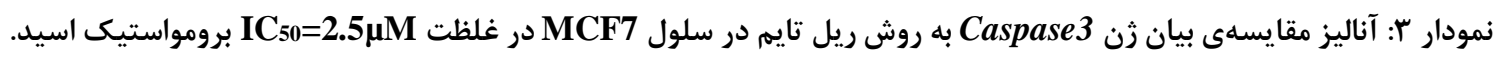

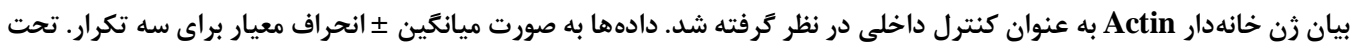

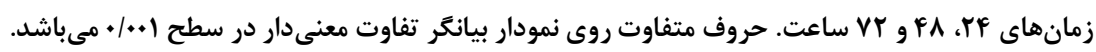




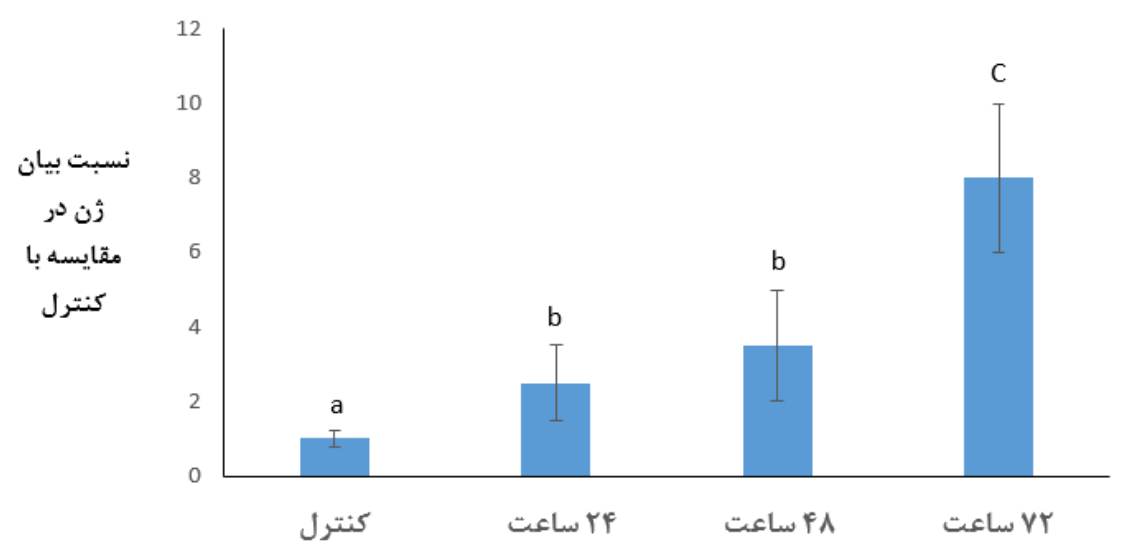

نمودار F: آناليز مقايسهى بيان زن Caspase8 به روش ريل تايم در سلول MCF7 در غلظت IC50=2.5PM برومواستيك اسيد.

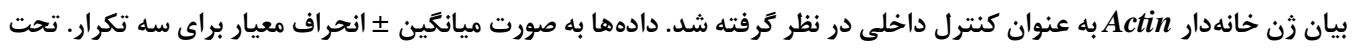

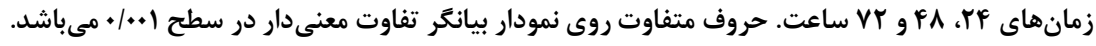

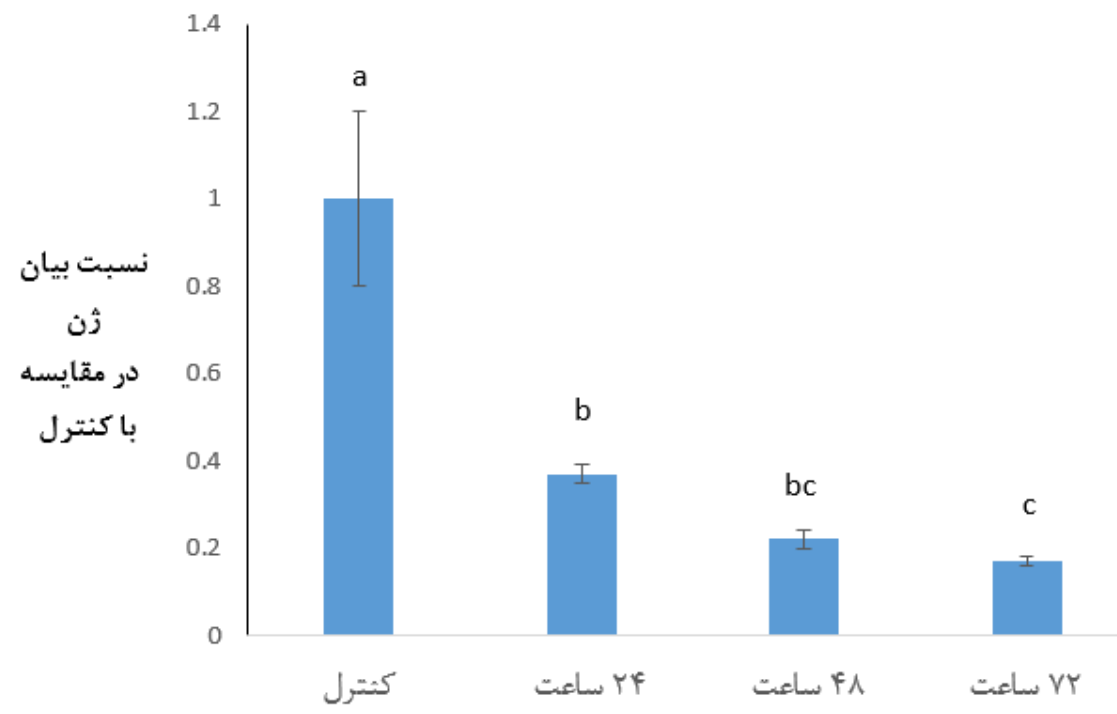

نمودار ه: آناليز مقايسهى بيان زن Bim به روش ريل تايم در سلول MCF7 در غلظت IC50=2.5 بM برومواستيك اسيد.

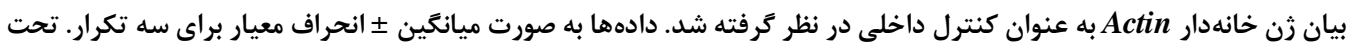

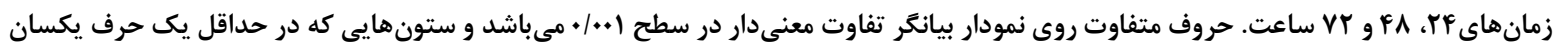
هستند تفاوت معنى دارى ندارند.

كه اين نتايج با نتايج حاصل از بيان زن نيز تطبيق خوبى داري بحث

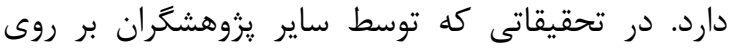

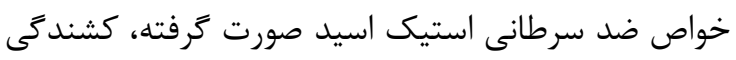
بسيار خوب اين ملكول و تاثير زمان بر آن، نتايجى مشابه آند

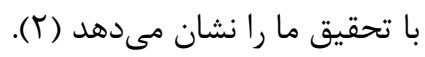

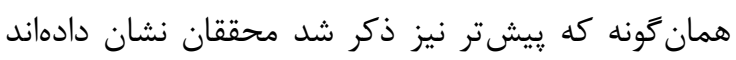

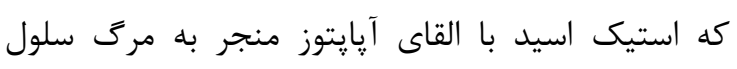

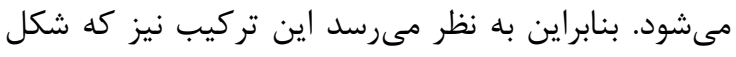

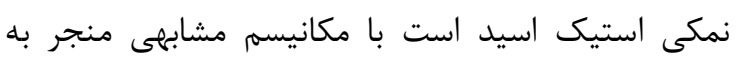
در اين تحقيق، از مقايسه اثر زمان بر درصد كشندگى در

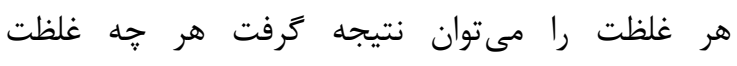

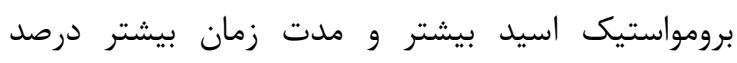

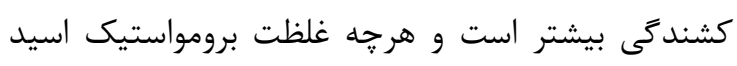

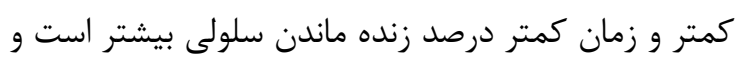

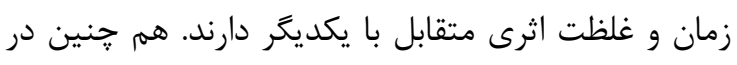

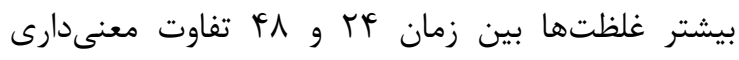

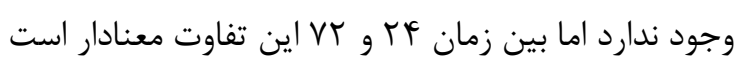


Cysteine-dependent aspartate صورت آغاز

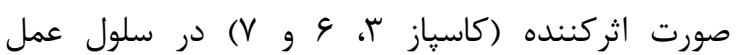

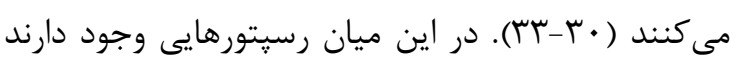

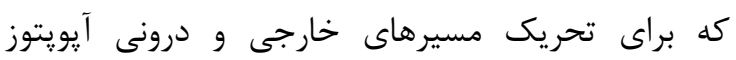
بايستى تعادل بين فاكتورهاى ييش آيويتوز (يروآيويتوز و Bak Bax Bid آيويتيك (Bcl2 , Bcl-X) ايجاد نمايند. اين تعادل

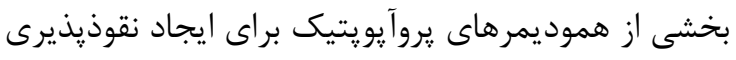

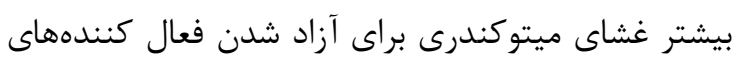

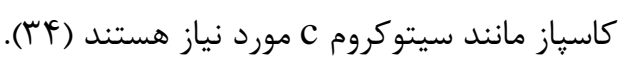

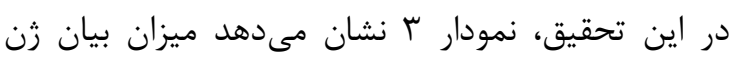
VT د Caspase3

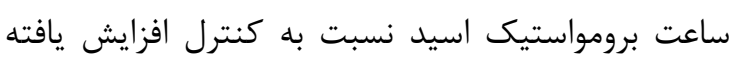

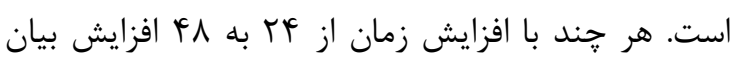

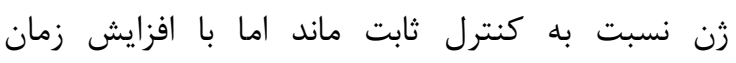

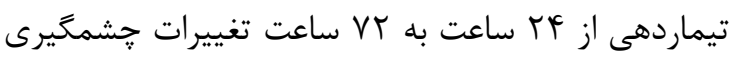

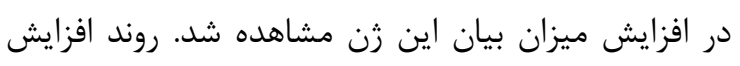
Caspase3 بيان زن Caspase8

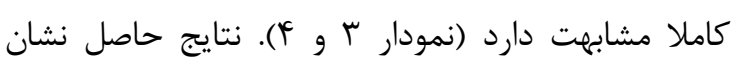

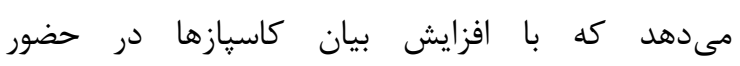
برومواستيك اسيد احتمال القاى آيايتوز توسط اين تركيب

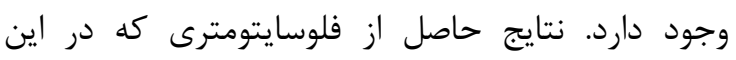

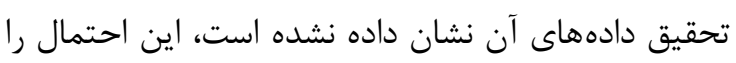

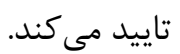

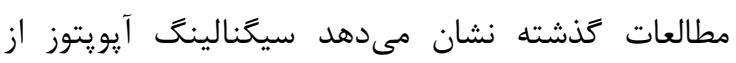

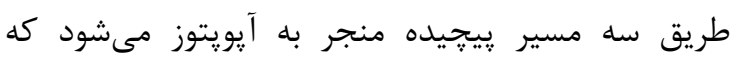

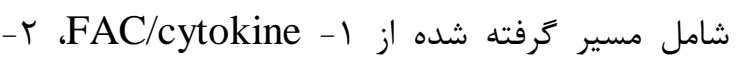

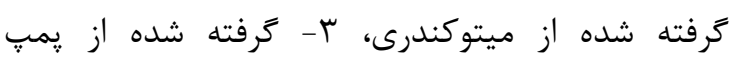
كليسيم/ شبكه اندويلاسمى است. در بيان اين سه مسئو مسير

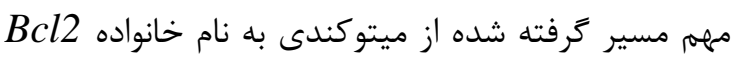

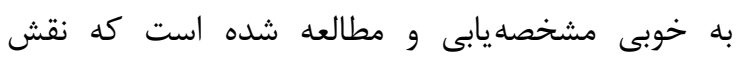

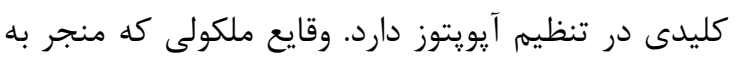

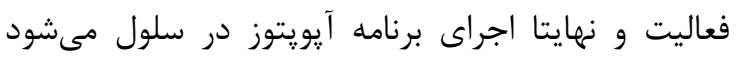

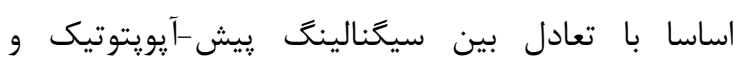

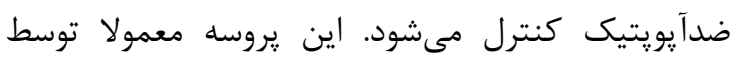

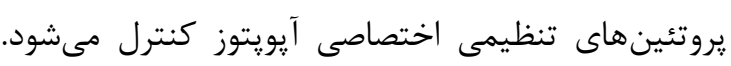

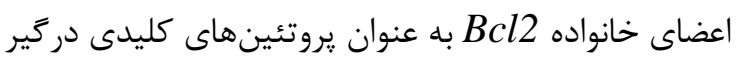
در شكل گيرى كانالهاى آيويتيك ميتو كندريايى و تنظيم
مرك سلولى مىشود. بنابراين در اين مطالعه، تلاش شده

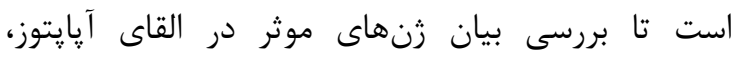
مكانيسم ضدسرطانى اين ملكول مورد بحث و بررسى درى قرار كيرد. يك يروتئين كليدى در آيويتوز القا شده توسط عوامل

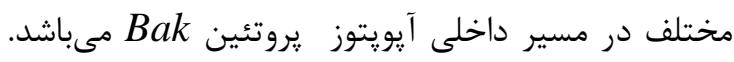

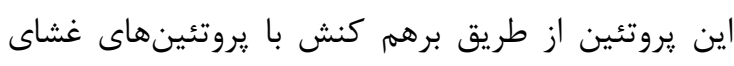
ميتوكندرى موجب افزايش نفوذيذيرى اين غشنا و و آزاد

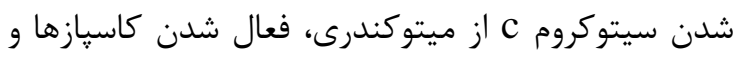

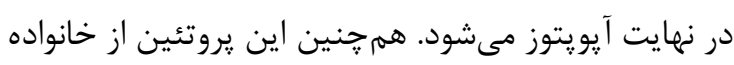

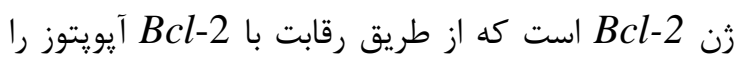
افزايش مى دهد و زن آن داراى يك قسمت آغاز

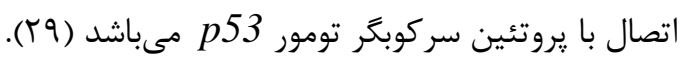

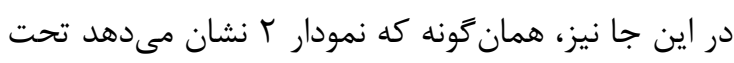

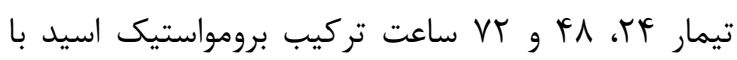

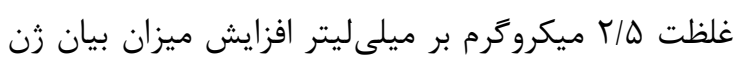

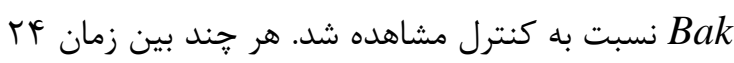

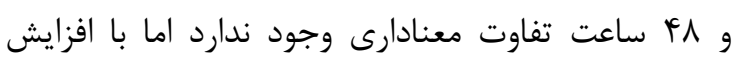

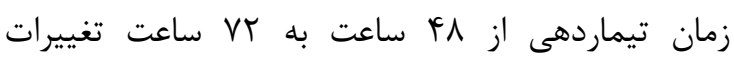

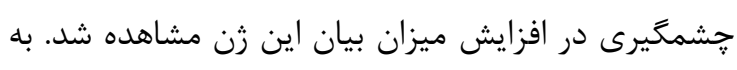

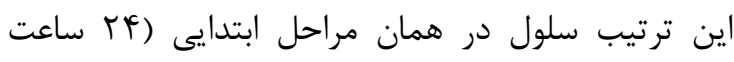

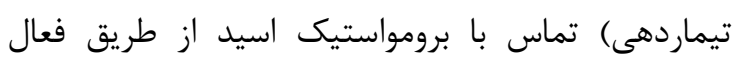

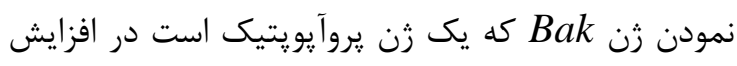

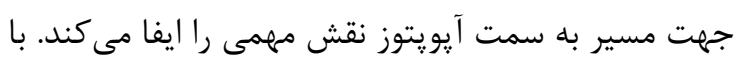
كذشت زمان بيان زن افزايش مئ ميابد. بنابراين مى متوان

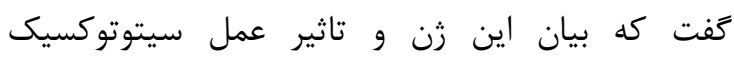

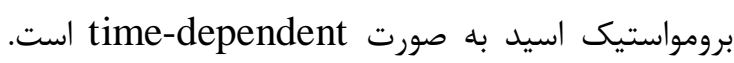

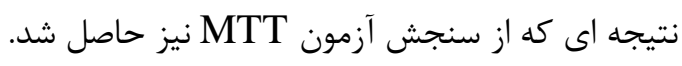

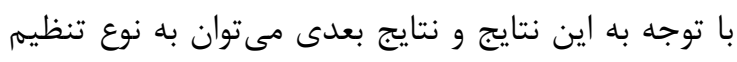

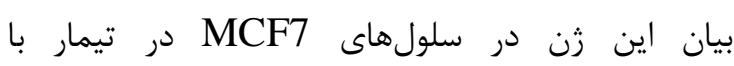

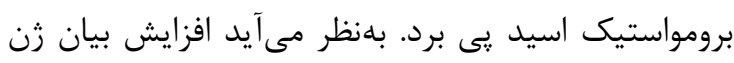

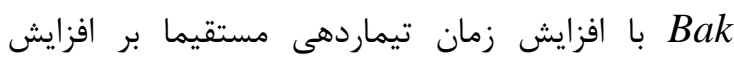

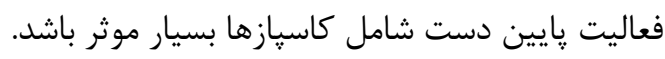

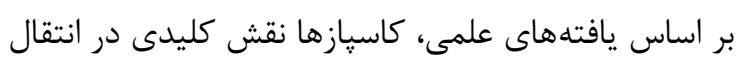

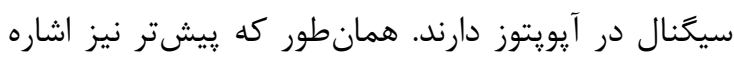

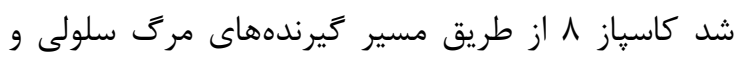

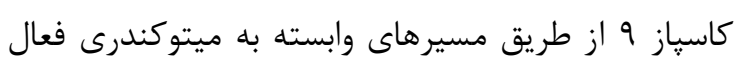

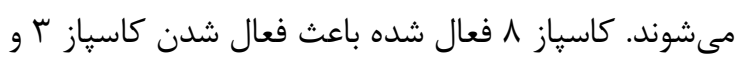

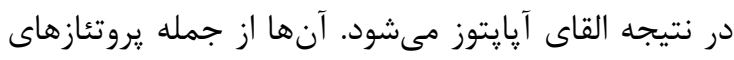


بيرونى ميتوكندرى را كاهش داده و منجر به فعال شدن

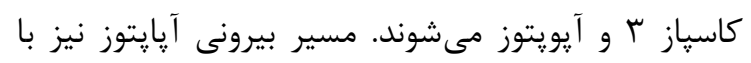

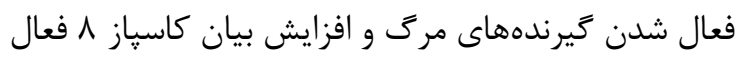

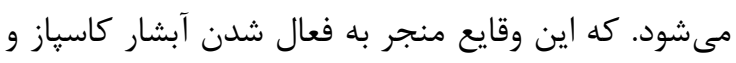

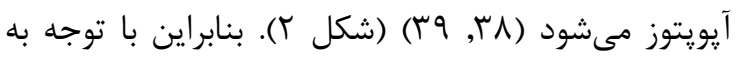

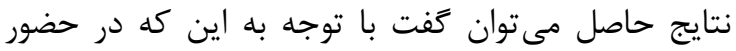

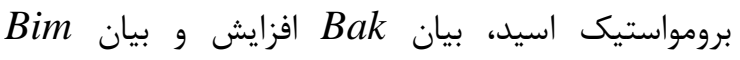

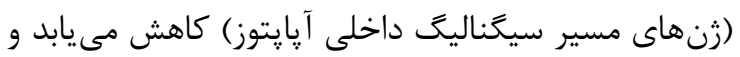
بيان كاسياز ^ (از زن هاى مسير سيخناليخ بيرونى آيإِتوز )

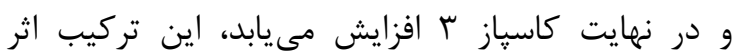

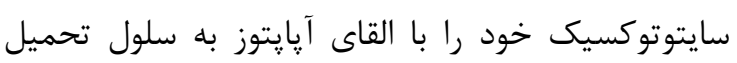

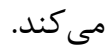

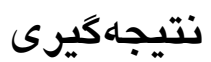

نتايج مطالعات ما نشان مىدهد كه مولكول برومواستيك اسيد يك تركيب ضدسرطانى قوى با IC50 بسيار ريايين در مقايسه با داروهاى استاندارد است كه اثر سيتوتوكسيك

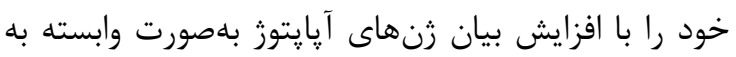

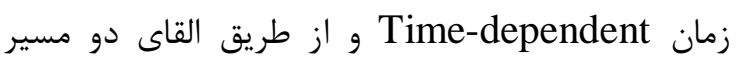

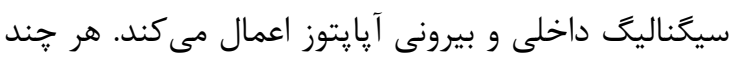

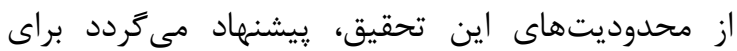

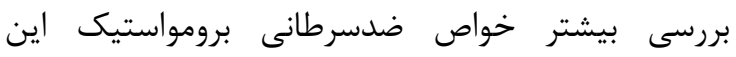

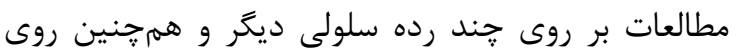

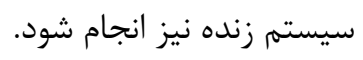

\section{تعارض منافع}

نويسندكان اعلام مى دارند كه هيج تعارض منافعى در يزولهش حاضر وجود ندارد.

\section{References}

1. Terasaki M, Ito H, Kurokawa H, Tamura M, Okabe S, Matsui $\mathrm{H}$, et al. Acetic acid is an oxidative stressor in gastric cancer cells. Journal of clinical biochemistry and nutrition. 2018;63(1):36-41.

2. Okabe S, Okamoto T, Zhao CM, Chen D, Matsui $\mathrm{H}$. Acetic acid induces cell death: an in vitro study using normal rat gastric mucosal cell line and rat and human gastric cancer and mesothelioma cell lines. Journal of
نفوذيذيرى ميتوكندرى و مسير سيخنالينگ آيويتيك

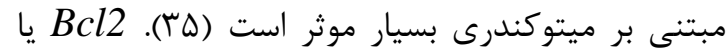

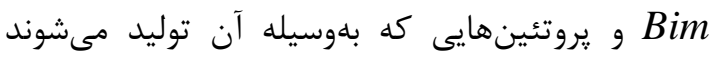

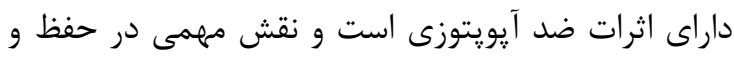

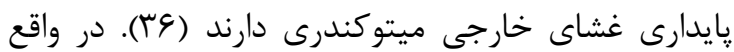
سيگنالهاى تحريك كننده : يروسه آيويتوز حاصل تعادل بين يروتئينهاى آيويتيك و ضدآيويتيك است.

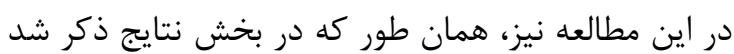

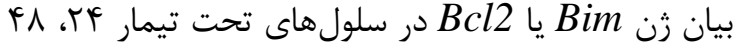
و ساعت برومواستيك اسيد نسبت به كنترل كاهش

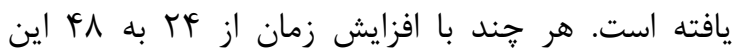
كاهش نسبت به كنترل ثابت ماند. يس از آن با افزايش مدت زمان تيماردهى (VY ساعت) ميزان بيان اين زن بيشترين كاهش را نسبت به كنترل نشان ميدهد. از ران

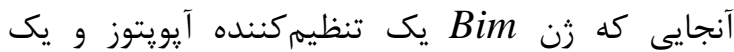

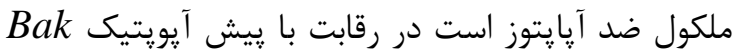
نمى تواند مانع فعاليت آيويتوز در زمان هاى مختلف شود.

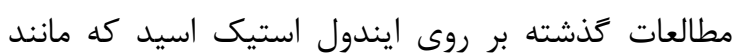
برومو استيك اسيد مشتقى از استيك اسيد است نيز نشان

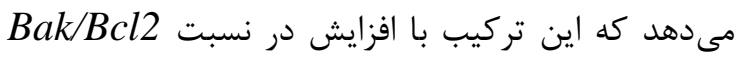

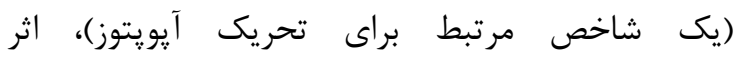
سيتوتوكسيك خود را اعمال مى كند كه با نتايج مطالعه حاضر مطابقت دارد. همرجنين افزايش فعاليت كاسياز گ ^ نيز با افزايش مدت زمان تيماردهى مشاهده شده بود

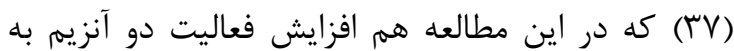
عملكرد بهتر يروآيويتيكها كمك نمود.

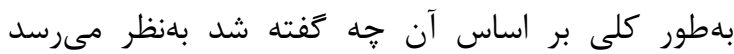

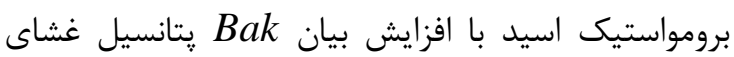

gastroenterology and hepatology. 2014;29 (4) :65-9.

3. Bonnet S, Archer SL, Allalunis-Turner J, Haromy A, Beaulieu C, Thompson R, et al. A mitochondria- $\mathrm{K}+$ channel axis is suppressed in cancer and its normalization promotes apoptosis and inhibits cancer growth. Cancer cell. 2007;11(1):37-51.

4. Kim JS, Cho IA, Kang KR, Lim H, Kim TH, Yu $\mathrm{SK}$, et al. Reversine induces caspase-dependent 
apoptosis of human osteosarcoma cells through extrinsic and intrinsic apoptotic signaling pathways. Genes \& genomics. 2019;41(6):65765.

5. Zhang G, Ma F, Li L, Li J, Li P, Zeng S, et al. Palbociclib triggers apoptosis in bladder cancer cells by Cdk2-induced Rad9-mediated reorganization of the Bak.Bcl-xl complex. Biochemical pharmacology. 2019;163:133-41.

6. Kazi A, Sun J, Doi K, Sung SS, Takahashi Y, Yin $\mathrm{H}$, et al. The $\mathrm{BH} 3$ alpha-helical mimic BH3-M6 disrupts Bcl-X(L), Bcl-2, and MCL-1 protein-protein interactions with Bax, Bak, Bad, or Bim and induces apoptosis in a Bax- and Bim-dependent manner. The Journal of biological chemistry. 2011;286(11):9382-92.

7. Badr G, Sayed EA, Waly H, Hassan KA, Mahmoud MH, Selamoglu Z. The Therapeutic Mechanisms of Propolis Against CCl4 Mediated Liver Injury by Mediating Apoptosis of Activated Hepatic Stellate Cells and Improving the Hepatic Architecture through PI3K/AKT/mTOR, TGF-beta/Smad2, Bcl2/BAX/P53 and iNOS Signaling Pathways. Cellular physiology and biochemistry : international journal of experimental cellular physiology, biochemistry, and pharmacology. 2019;53(2):301-22.

8. Flentke GR, Baulch JW, Berres ME, Garic A, Smith SM. Alcohol-mediated calcium signals dysregulate pro-survival Snai2/PUMA/Bcl2 networks to promote p53-mediated apoptosis in avian neural crest progenitors. Birth defects research. 2019;111(12):686-99.

9. Liao W, Liu J, Liu B, Huang X, Yin Y, Cai, et al. JIB04 induces cell apoptosis via activation of the $\mathrm{p} 53 / \mathrm{Bcl} 2 /$ caspase pathway in $\mathrm{MHCC} 97 \mathrm{H}$ and HepG2 cells. Oncology reports. 2018;40(6):3812-20.

10. Roy S, Sil A, Chakraborty T. Potentiating apoptosis and modulation of p53, Bcl2, and Bax by a novel chrysin ruthenium complex for effective chemotherapeutic efficacy against breast cancer. Journal of cellular physiology. 2019;234(4):4888-909.

11. Tousson E, Rafat BM, Hessien M, El Barbary AA, Sami A. P53 and Bcl2 apoptosis proteins in meso 2,3-dimercaptosuccinic acid treated leadintoxicated rabbits. Toxicology and industrial health. 2011;27(3):271-8.

12. Song W, Song C, Chen Y, Du M, Hu P, Liu A, et al. Polysaccharide-induced apoptosis in H22 cells through G2/M arrest and BCL2/BAX caspase-activated Fas pathway. Cellular and molecular biology. 2015;61(7):88-95.

13. Li CL, Chang L, Guo L, Zhao D, Liu HB, Wang QS, et al. beta-elemene induces caspasedependent apoptosis in human glioma cells in vitro through the upregulation of Bax and Fas/ FasL and downregulation of Bcl-2. Asian Pacific journal of cancer prevention : APJCP. 2014;15(23):10407-12.

14. Liang CZ, Zhang JK, Shi Z, Liu B, Shen CQ, Tao HM. Matrine induces caspase-dependent apoptosis in human osteosarcoma cells in vitro and in vivo through the upregulation of Bax and Fas/FasL and downregulation of Bcl-2. Cancer chemotherapy and pharmacology. 2012;69(2):317-31.

15. Mendilcioglu I, Karaveli S, Erdogan G, Simsek M, Taskin O, Ozekinci M. Apoptosis and expression of Bcl-2, Bax, p53, caspase-3, and Fas, Fas ligand in placentas complicated by preeclampsia. Clinical and experimental obstetrics \& gynecology. 2011;38(1):38-42.

16. Hikita H, Takehara T, Kodama T, Shimizu S, Shigekawa M, Hosui A, et al. Delayed-onset caspase-dependent massive hepatocyte apoptosis upon Fas activation in Bak/Baxdeficient mice. Hepatology. 2011;54(1):240-51.

17. Gonzaga ACR, Campolina-Silva GH, WerneckGomes H, Moura-Cordeiro JD, Santos LC, Mahecha GAB, et al. Profile of cell proliferation and apoptosis activated by the intrinsic and extrinsic pathways in the prostate of aging rats. The Prostate. 2017;77(9):937-48.

18. Toth C, Funke S, Nitsche V, Liverts A, Zlachevska V, Gasis $\mathrm{M}$, et al. The role of apoptosis repressor with a CARD domain (ARC) in the therapeutic resistance of renal cell carcinoma (RCC): the crucial role of ARC in the inhibition of extrinsic and intrinsic apoptotic signalling. Cell communication and signaling : CCS. 2017;15(1):16.

19. Managit C, Sakurai H, Saiki I. Ethanolic extract of Thevetia peruviana flowers enhances TNFalpha and TRAIL-induced apoptosis of human cervical cancer cells via intrinsic and extrinsic pathways. Oncology letters. 2017;13(4):2791-8.

20. Lan T, Zhao H, Xiang B, Wang J, Liu Y. Suture compression induced midpalatal suture chondrocyte apoptosis with increased caspase-3, caspase-9, Bad, Bak, Bax and Bid expression. Biochemical and biophysical research communications. 2017;489(2):179-86.

21. Yang Q,Li S, Fu Z, Lin B, Zhou Z, Wang Z, et al. Shikonin promotes adriamycininduced apoptosis by upregulating caspase 3 and caspase8 in osteosarcoma. Molecular medicine reports. 2017;16(2):1347-52.

22. Medina-Reyes EI, Mancera-Rodriguez MA, Delgado-Buenrostro NL, Moreno-Rodriguez A, Bautista-Martinez JL, Diaz-Velasquez CE, et al. Novel thiosemicarbazones induce high toxicity in estrogen-receptor-positive breast cancer cells (MCF7) and exacerbate cisplatin effectiveness 
in triple-negative breast (MDA-MB231) and lung adenocarcinoma (A549) cells. Investigational new drugs. 2020;38(3):558-73

23. Buahorm S, Puthong S, Palaga T, Lirdprapamongkol K, Phuwapraisirisan P, Svasti J, et al. Cardanol isolated from Thai Apis mellifera propolis induces cell cycle arrest and apoptosis of BT-474 breast cancer cells via p21 upregulation. Daru : journal of Faculty of Pharmacy, Tehran University of Medical Sciences. 2015;23 (1):1-11.

24. Liu C, Zhang RR, Wang YM, Zhang J, Wang Q, Cheng AW, et al. Supercritical CO2 fluid extraction of croton crassifolius Geisel root: Chemical composition and anti-proliferative, autophagic, apoptosis-inducing, and related molecular effects on A549 tumour cells. Phytomedicine: international journal of phytotherapy and phytopharmacology. 2019 Aug;61:152846.

25. Wang X, Fu Z, Chen Y, Liu L. Fas expression is downregulated in gastric cancer. Molecular medicine reports. 2017;15(2):627-34.

26. Nasim Borhani MM, SorayaSaleh Gargari, Marefat Ghaffari Novin, Ardalan Mansouri, Mir Davood Omrani. Decreased Expression of Proapoptotic Genes Caspase-8- and BCL2Associated Agonist of Cell Death (BAD) in Ovarian Cancer. Clinical Ovarian and Other Gynecologic Cancer. 2014;7(1-2):18-23.

27. Cheng F, Pan Y, Lu YM, Zhu L, Chen S. RNABinding Protein Dnd1 Promotes Breast Cancer Apoptosis by Stabilizing the Bim mRNA in a miR-221 Binding Site. BioMed research international. 2017;2017:9596152.

28. Chen L, Wang L, Yan J, Ma C, Lu J, Chen G, et al. 131I-labeled monoclonal antibody targeting neuropilin receptor type-2 for tumor SPECT imaging. International journal of oncology. 2017;50(2):649-59.

29. Vartak SV, Iyer D, Santhoshkumar TR, Sharma S, Mishra A, Goldsmith G, et al. Novel BCL2 inhibitor, Disarib induces apoptosis by disruption of BCL2-BAK interaction. Biochemical pharmacology. 2017;131:16-28.

30. Zhu G, Qiu W, Li Y, Zhao C, He F, Zhou M, et al. Sublytic C5b-9 Induces Glomerular Mesangial Cell Apoptosis through the Cascade Pathway of MEKK2-p38 MAPK-IRF- -
TRADD-Caspase 8 in Rat Thy-1 Nephritis. Journal of immunology. 2017;198(3):1104-18.

31. Peng X, Gan J, Wang Q, Shi Z, Xia X. 3Monochloro-1,2-propanediol

(3-MCPD) induces apoptosis via mitochondrial oxidative phosphorylation system impairment and the caspase cascade pathway. Toxicology. 2016;372:1-11.

32. Deng W, Yang W, Zeng J, Abdalla AE, Xie J. Mycobacterium tuberculosis PPE32 promotes cytokines production and host cell apoptosis through caspase cascade accompanying with enhanced ER stress response. Oncotarget. 2016;7(41):67347-59.

33. Singh R, Banerjee C, Ray A, Rajamani P, Mazumder S. Fluoride-induced headkidney macrophage cell apoptosis involves activation of the CaMKIIg-ERK 1/2-caspase- 8 axis: the role of superoxide in initiating the apoptotic cascade. Toxicology research. 2016;5(5):147789.

34. Frenzel A, Labi V, Chmelewskij W, Ploner C, Geley S, Fiegl H, et al. Suppression of B-cell lymphomagenesis by the $\mathrm{BH} 3$-only proteins Bmf and Bad. Blood. 2010;115(5):995-1005.

35. Ghobrial IM, Witzig TE, Adjei AA. Targeting apoptosis pathways in cancer therapy. CA: a cancer journal for clinicians. 2005;55(3):17894.

36. Shigemi H, Yamauchi T, Tanaka Y, Ueda T. Novel leukemic cell lines resistant to clofarabine by mechanisms of decreased active metabolite and increased antiapoptosis. Cancer science. 2013;104(6):732-9.

37. Yu JS, Lee D, Lee SR, Lee JW, Choi CI, Jang TS, et al. Chemical characterization of cytotoxic indole acetic acid derivative from mulberry fruit )Morus alba L.) against human cervical cancer. Bioorganic chemistry. 2018;76:28-36.

38. Wali JA, Masters SL, Thomas HE. Linking metabolic abnormalities to apoptotic pathways in Beta cells in type 2 diabetes. Cells. 2013;2 (2):266-83

39. Czabotar PE, Lessene G, Strasser A, Adams JM. Control of apoptosis by the BCL-2 protein family: implications for physiology and therapy. Nature reviews Molecular cell biology. 2014;15(1):49-63. 